\title{
STUDY OF ADVANCED LAPAROSCOPY BEYOND CHOLECYSTECTOMY
}

\author{
Kulkarni Prachi $S^{1}$, Bhate Jidnyasa $T^{2}$
}

${ }_{1}^{1}$ Assistant Professor, Department of General Surgery, BJ Government Medical College, Pune, Maharashtra, India.

${ }^{2}$ Assistant Professor, Department of General Surgery, BJ Government Medical College, Pune, Maharashtra, India. ABSTRACT

\section{BACKGROUND}

Laparoscopic cholecystectomy revolutionised biliary surgery and has become the index operation. This study attempts to evaluate the types of advanced laparoscopic surgeries being performed, their efficacy and suitability at this institution.

\section{MATERIALS AND METHODS}

This study is carried out at our tertiary care institute over a span of 2 years. Patients undergoing advanced laparoscopic procedures on elective basis were studied. Procedures considered for purpose of study were: Adhesiolysis, Laparoscopic Colorectal procedures, Diagnostic Laparoscopy (with omental biopsy), Orchidectomy, Mesh Repair, TAPP and TEPP.

\section{RESULTS}

The highest number of patients belonged to the productive age group (21-50 years) consisting of $79 \%$ of total patients. The procedure performed most commonly was Laparoscopic Adhesiolysis (29.5\%).

\section{CONCLUSION}

The overall outcome was satisfactory with an early discharge and early return to normal activities.

\section{KEY WORDS}

Advanced Laparoscopy; Adhesiolysis; TAPP (Transabdominal Preperitoneal); TEP (Total Extraperitoneal).

HOW TO CITE THIS ARTICLE: Prachi KS, Jidnyasa BT. Study of advanced laparoscopy beyond cholecystectomy. J. Evolution Med. Dent. Sci. 2018;7(30):3373-3376, DOI: 10.14260/jemds/2018/761

\section{BACKGROUND}

It is indeed remarkable that within five years of its performance in March 1987 by Mouret1,2,3 from France, who performed the first human Laparoscopic Cholecystectomy (LC) and in September $1992 \mathrm{NIH}$ consensus conference concluded that LC is the gold standard treatment for gall bladder lithiasis.

It is rapidly progressed by perseverance due to reduction in post-operative morbidity and shorter stay in hospital and convalescence than open cholecystectomy.

No other surgical development has had such pivotal impact on abdominal operations as laparoscopic cholecystectomy, not only LC revolutionised biliary surgery but has become the index operation. For variety of other visceral and retroperitoneal laparoscopic procedure is the bottom line to compare the results.

Advances in surgical endeavours; laparoscopic skills of retraction, dissection and suturing and other devices e.g. the light source from halogen to xenon and more advice like ultrasonic shears, vessel sealing system has and endostaplers for anastomosis making advances in acceptance to surgeries beyond LC, the advances in other visceral surgeries. Having said all this, there can be no doubt that laparoscopy is the most compelling and dynamic force driving surgical progress and endeavour in the current era.

'Financial or Other Competing Interest': None.

Submission 02-07-2018, Peer Review 15-07-2018,

Acceptance 17-07-2018, Published 23-07-2018.

Corresponding Author:

Dr. Bhate Jidnyasa T,

C6, Bldg. No. 5, Leela Park Society,

Shivtirthnagar, Kothrud, Pune-411038,

Maharashtra, India.

E-mail: jidnyasabhate@gmail.com

DOI: $10.14260 /$ jemds/2018/761

\section{(c) (i) $(9$}

This "Study of Advanced Laparoscopy beyond Cholecystectomy" attempts to study the types of advanced laparoscopic surgeries being performed, their efficacy and suitability at this institution, as also to study the age and sex distribution, disease profile of patients undergoing advanced laparoscopies and to study the duration of surgery, post-op complications and duration of post-op hospital stay.

\section{Aims and Objectives}

1. To study the types of advanced laparoscopic surgeries being performed, their efficacy and suitability at this institution.

2. To study the age and sex distribution, disease profile of patients undergoing advanced laparoscopies.

3. To study the duration of surgery, post-op complications and duration of post-op hospital stay.

\section{MATERIALS AND METHODS}

It is a descriptive study. This study is carried out at our tertiary care institute over a span of 2 years. Patients undergoing advanced laparoscopic procedures on elective basis were studied.

\section{Inclusion Criteria}

All patients undergoing advanced laparoscopic procedures on elective basis are to be studied prospectively.

\section{Exclusion Criteria}

1. Patients unfit for general anaesthesia.

2. Patients in whom there was technical inability to perform complete laparoscopic procedure, and hence converted to open procedure.

Procedures considered for purpose of study were-

1. Adhesiolysis: Post-operative adhesions are the commonest cause of Small Bowel Obstruction (SBO), a 
frequent surgical emergency. ${ }^{4}$ According to the EAES (European Association of Endoscopic Surgery) recommendations, in case of clinical and radiological evidence of small bowel obstruction non-responding to conservative management, laparoscopy may be performed using an open access technique. If adhesions are found at laparoscopy, cautious laparoscopic 5 adhesiolysis can be attempted for release of small bowel obstruction. ${ }^{6}$

2. Laparoscopic colorectal procedures: Left Hemicolectomy, Right Hemicolectomy, Anterior Resection, APR. The first laparoscopic colorectal surgery was described in the Medical Literature in $1991{ }^{7}$

Criteria: Surgeon with experience performing laparoscopically-assisted colorectal operations.

No disease in rectum or prohibitive abdominal adhesions.

No advanced local or metastatic disease.

Not indicated for acute bowel obstruction or perforation from cancer.

Thorough abdominal exploration is required. Consider preoperative marking of small lesions.

Consider more extensive colectomy for patients with a strong family history of colon cancer or young age. Resection needs to be complete to be considered curative.

3. Diagnostic laparoscopy (with omental biopsy).

4. Excision of cysts, de-roofing of cyst.

5. Gastrojejunostomy, Jejunojejunostomy: Choi8 reported that patients treated with laparoscopic GJ did not experience complications in the early post-operative period. Compared with open GJ, laparoscopic GJ reduced morbidity, mortality and the incidence of post-operative complications, allowed for earlier oral feeding and shortened the hospital stay.

6. Live omentopexy.

7. Orchidectomy, Varicocelectomy: Current recommendations for post-pubertal men are as follows for laparoscopic intervention:

- Younger than 32 years with a unilateral undescended testis and normal contralateral testisOrchiectomy.

- $\quad$ Older than 32 years with a unilateral undescended testis- Close observation and physical examination (orchiopexy vs orchiectomy if difficult to examine).

This recommendation is based on the relative risk of testicular cancer along with the risks associated with anaesthesia. Nothing contraindicates intervention for undescended testis in prepubertal boys. ${ }^{9,10}$

In a study by McManus et $\mathrm{al}^{11}$ Laparoscopic Varicocelectomy [LVL] resulted in shorter operative times and fewer negative outcomes like persistent or recurrent varicoceles.

8. Diaphragmatic repair with gastropexy: The laparoscopic approach has advantages including reduced hospital stay, excellent visualisation of the defect even for obese patients and improved cosmesis. ${ }^{12}$ First laparoscopic repair was done by Kuster ${ }^{13}$ et al in 1992 and since then 25 cases have been reported. In no patient was post-op complications like pleural effusion, wound infection, atelectasis, DVT or pulmonary embolism observed.
9. Mesh Repair, TAPP, TEPP: The indications for performing a laparoscopic hernia repair are essentially the same as repairing the hernia conventionally. ${ }^{14,15}$ There are, however, certain situations where laparoscopic hernia repair may offer definite benefit over conventional surgery to the patients. These include bilateral inguinal hernias and recurrent inguinal hernias. In recurrent hernia surgery failure rate is as high as 25 to 30 percent, if again repaired by open surgery. The distorted anatomy after repeated surgery makes it more prone to recurrence and other complications like ischaemic orchitis. In recurrent hernia, the laparoscopic approach offers repair through the inner healthy tissues with clear anatomical planes and thus a lower failure rate. In laparoscopic bilateral repair with three ports technique, there is simultaneous access to both sides without any additional trocar placement. Even in patients with clinically unilateral defect after entering inside the abdominal cavity there is 20-50 percent incidence of a contralateral asymptomatic hernia being found, which can be repaired simultaneously without any additional morbidity of the patient.

After some experience, most cases of inguinal hernia can be treated laparoscopically. ${ }^{14,15,16}$

10. Pericystectomy.

11. Splenectomy.

\section{RESULTS}

65 patients undergoing advanced laparoscopic procedures on elective basis were studied. Total no. of patients $(n)=65$.

\begin{tabular}{|c|c|c|}
\hline$<20$ years & 04 & $06 \%$ \\
\hline $21-30$ years & 19 & $29 \%$ \\
\hline $31-40$ years & 18 & $28 \%$ \\
\hline $41-50$ years & 14 & $22 \%$ \\
\hline$>51$ years & 10 & $15 \%$ \\
\hline Total & $\mathbf{6 5}$ & $\mathbf{1 0 0} \%$ \\
\hline \multicolumn{2}{|c|}{ Table 1. Age Distribution } \\
\hline
\end{tabular}

\begin{tabular}{|c|c|c|}
\hline Male & 23 & $36 \%$ \\
\hline Female & 42 & $64 \%$ \\
\hline Total & $\mathbf{6 5}$ & $\mathbf{1 0 0 \%}$ \\
\hline \multicolumn{3}{|c|}{ Table 2. Sex Distribution } \\
\hline
\end{tabular}

\begin{tabular}{|c|c|c|}
\hline Diagnosis & No. of Patients & $\mathbf{\%}$ \\
\hline $\begin{array}{c}\text { Post-op Adhesive Intestinal } \\
\text { Obstruction }\end{array}$ & 19 & 29.5 \\
\hline Upper GIT & 10 & 16.5 \\
\hline Colorectal Malignancies & 08 & 12 \\
\hline Hydatid Cyst & 12 & 18 \\
\hline Hernias & 10 & 15 \\
\hline Renal, Gonadal & 06 & 09 \\
\hline Total & $\mathbf{6 5}$ & $\mathbf{1 0 0}$ \\
\hline
\end{tabular}

Table 3. Diagnosis

\begin{tabular}{|c|c|c|}
\hline Laparoscopic Procedure & No. of Patients & $\mathbf{\%}$ \\
\hline Adhesiolysis & 19 & 29 \\
\hline Anterior Resection, APR & 03 & 04 \\
\hline $\begin{array}{c}\text { Diagnostic Laparoscopy (with } \\
\text { omental biopsy) }\end{array}$ & 01 & 01.5 \\
\hline Excision of cysts & 08 & 12 \\
\hline Deroofing of cyst & 01 & 01.5 \\
\hline Gastrojejunostomy & 05 & 07 \\
\hline
\end{tabular}




\begin{tabular}{|c|c|c|}
\hline Left Hemicolectomy & 02 & 03 \\
\hline Right Hemicolectomy & 02 & 03 \\
\hline Jejunojejunostomy & 01 & 01.5 \\
\hline Live Omentopexy & 02 & 03 \\
\hline Mesh Repair & 02 & 03 \\
\hline Orchidectomy & 02 & 03 \\
\hline Pericystectomy & 06 & 09 \\
\hline $\begin{array}{l}\text { Diaphragmatic Repair with } \\
\text { Gastropexy }\end{array}$ & 01 & 01.5 \\
\hline Splenectomy & 01 & 01.5 \\
\hline TAPP & 01 & 02 \\
\hline TEPP & 07 & 10 \\
\hline Varicocelectomy & 03 & 04.5 \\
\hline Total & 65 & 100 \\
\hline \multicolumn{3}{|c|}{ Table 4. Laparoscopic Procedure Performed } \\
\hline
\end{tabular}

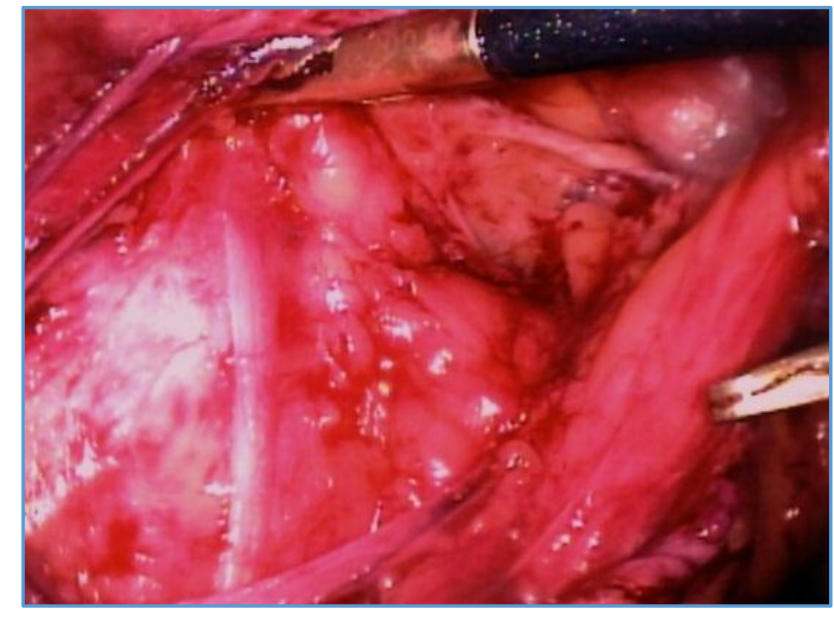

Figure 2. TAPP

\section{Laparoscopic Colorectal Procedures}

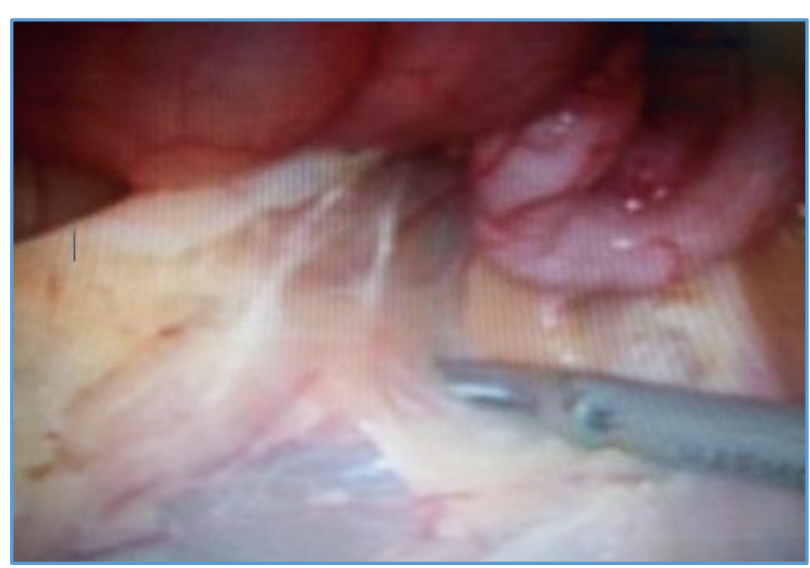

\section{Figure 3. Caecal Dissection at Right Hemicolectomy}

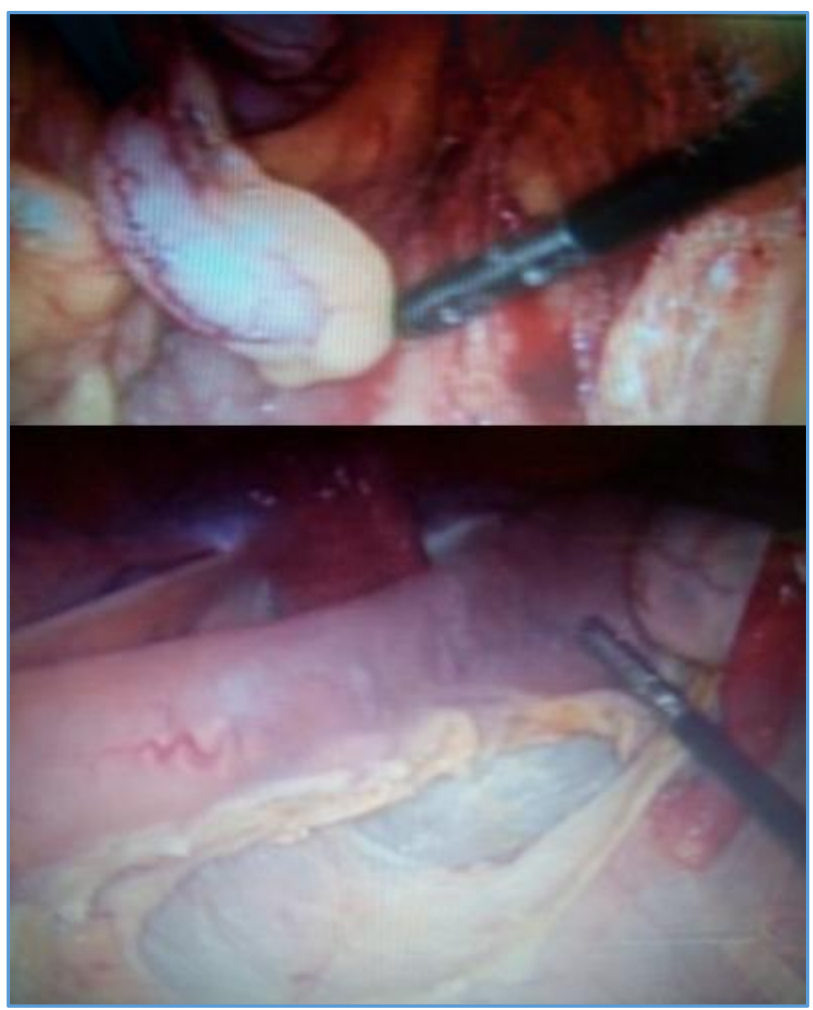

Figure 4. Caecal Dissection at Right Hemicolectomy

Figure 1. Laparoscopic Adhesiolysis 


\section{DISCUSSION}

65 patients undergoing advanced laparoscopic procedures on elective basis were studied. The highest number of patients belonged to the productive age group (21-50 years) consisting of $79 \%$ of total patients. In this study, the sex ratio of patients shows a female preponderance with $64 \%$ of patients undergoing elective advanced procedures being females.

The procedure performed most commonly was Laparoscopic Adhesiolysis (29.5\%). Laparoscopic Gastrojejunostomy was done in $7 \%$ of patients for gastric outlet obstruction. Of these 4 patients had gastric outlet obstruction and 1 had duodenal stricture. Among these, 4 patients underwent Stapler anastomosis and one patient with Gastric outlet obstruction underwent manually sutured anastomosis with silk. In one patient with jejunal stricture underwent resection and stapler jejunojejunal anastomosis was done.

As compared to Hazrat ${ }^{10}$ et al, fewer Orchidopexies (97\% vs $33 \%$ ) and more Orchidectomies ( $3 \%$ vs $66 \%$ ) were done and average operative time for these procedures was more (20 mins vs 45 mins).

In no patient was post-op complication like pleural effusion, wound infection, atelectasis, DVT or pulmonary embolism observed.

The time taken for completion of procedures was between 1 and 2 hours in $50 \%$ of the patients. $22 \%$ of procedures were completed within 30 minutes and most of these included Adhesiolysis, some of which were finished within a mere 20 minutes. Only one surgery lasted more than 3 hours, which was diaphragmatic repair with gastropexy. Of the remaining, $17 \%$ took between 2 and 3 hours to completion and another $9 \%$ took between 30 and 40 minutes.

Post-op hospital stay was reduced in these patients with $56 \%$ being discharged within 5 days of operation. Another $27 \%$ were discharged by $10^{\text {th }}$ day of operation. Only $17 \%$ patients stayed after $11^{\text {th }}$ post-op day.

Post-op fever and wound infection were seen each in $12 \%$ of patients, 3 of whom had undergone extracorporeal anastomoses, 1 splenectomy, 1 gossypiboma excision and 1 varicocelectomy.

Of the $9 \%$ patients with post-op ileus, half had undergone extracorporeal anastomoses, 1 had gossypiboma, 1 with diaphragm repaired and 1 with adhesiolysis done. Post-op fistula was seen in 2 patients only- 1 with gossypiboma and other with adhesiolysis done.

Of the 7 patients undergoing TEPP, 14\% developed complications as compared to Payne et al ${ }^{17}(6 \%)$.

Of the 1 patient undergoing TAPP, 0\% developed complications as compared to Payne et al (12\%).

\section{CONCLUSION}

1. The procedure performed most commonly was Laparoscopic Adhesiolysis.

2. The procedure that was most difficult to perform was Laparoscopic repair of diaphragmatic hernia with gastropexy.

3. The procedure with highest number of complications was Laparoscopic Adhesiolysis. However, the overall outcome was satisfactory with an early discharge and early return to normal activities.

\section{Recommendation}

Given the smaller sample size, a larger sample population size maybe worthwhile to consider for improving and verifying the accuracy of these trends.

\section{REFERENCES}

[1] Mouret G. From the first laparoscopic cholecystectomy to the frontiers of laparoscopic surgery: the prospective futures. Dig Surg 1991;8(2):124-5.

[2] NIH Consensus Conference. Gallstones and laparoscopic cholecystectomy. JAMA 1993;269(8):1018-24.

[3] Dubois F, Berthelot G, Levard H. Laparoscopic cholecystectomy: historic perspective and personal experience. Surg Laparosc Endosc 1991;1(1):52-7.

[4] John. Evolving trends in laparoscopic surgery. Knol 2008:29-30.

[5] Zalcman M, Sy M, Donckier V, et al. Helical CT signs in the diagnosis of intestinal ischemia in small-bowel obstruction. AJR Am J Roentgenol 2000;175(6):16017.

[6] Rodgers KE, di Zerega GS. Function of peritoneal exudates cells after abdominal surgery. J Invest Surg 1993;6(1):9-23.

[7] Advances in minimally invasive procedures. Journal of Family Practice 2005.

[8] Choi YB. Laparoscopic gastrojejunostomy for palliation of gastric outlet obstruction in unresectable gastric cancer. Surg Endosc 2002;16(11):1620-6.

[9] El-Gohary MA. Role of laparoscopy in the management of impalpable testes. Journal of Indian Association of Pediatric Surgeons 2006;11(4):207-10.

[10] Hazrat. Laparoscopic management of undescended testis. Laparoscopy 2008:23-4.

[11] McManus MC. Laparoscopic varicocele ligation: are there advantages compared with the microscopic subinguinal approach? Urology 2004;64(2):357-60.

[12] Craigie RJ, Mullassery D, Kenny SE. Laparoscopic repair of late presenting congenital diaphragmatic hernia. Hernia 2007;11(1):79-82.

[13] Kuster GG, Kline LE, Garzo G. Diaphragmatic hernia through the foramen of Morgagni: laparoscopic repair case report. J Laparoendoscopic Surgery 1992;2(2):93-100.

[14] Fitzgibbons RJ Jr, Camps J, Cornet DA, et al. Laparoscopic inguinal herniorrhaphy. Results of a multicenter trial. Ann Surg 1995;221(1):3-13.

[15] Memon MA, Cooper NJ, Memon B, et al. Meta-analysis of randomized clinical trials comparing open and laparoscopic inguinal hernia repair. $\mathrm{Br} \mathrm{J}$ Surg 2003;90(12):1479-92.

[16] Memon MA, Fitzgibbons RJ Jr. Assessing risks, costs and benefits of laparoscopic hernia repair. Annu Rev Med 1998;49:95-109.

[17] Payne JH Jr, Grininger LM, Izawa MT, et al. Laparoscopic or open inguinal herniorrhaphy? A randomized prospective trial. Arch Surg 1994;129(9):973-81. 